\title{
Very well-differentiated gastric carcinoma of intestinal type: analysis of diagnostic criteria
}

Tetsuo Ushiku ${ }^{1,2}$, Thomas Arnason ${ }^{1}$, Shinichi Ban ${ }^{3}$, Tsunekazu Hishima ${ }^{4}$, Michio Shimizu ${ }^{5}$, Masashi Fukayama ${ }^{2}$ and Gregory Y Lauwers ${ }^{1}$

${ }^{1}$ Department of Pathology, Massachusetts General Hospital, Boston, MA, USA; ${ }^{2}$ Department of Pathology, University of Tokyo, Tokyo, Japan; ${ }^{3}$ Department of Pathology, Saiseikai Kawaguchi General Hospital, Kawaguchi, Saitama, Japan; ${ }^{4}$ Department of Pathology, Tokyo Metropolitan Komagome Hospital, Tokyo, Japan and ${ }^{5}$ Department of Pathology, Saitama Medical University, International Medical Center, Hidaka City, Saitama, Japan

\begin{abstract}
Very well-differentiated gastric adenocarcinoma of intestinal type is a rare variant of gastric cancer characterized by low-grade nuclear atypia, and for which the diagnostic criteria and clinical behavior are not fully established. This study presents a detailed histologic, immunohistochemical, and clinical analysis of 21 cases. Nuclear atypia was mild in all cases. Characteristic architectural features of this gastric adenocarcinoma variant were pit and glandular anastomosis, spiky glands, distended glands, discohesive cells, abortive glands, and glandular outgrowth. At least three of these features were present in all the cases. Retrospective review of preoperative biopsies in $\mathbf{1 8}$ patients revealed that half of the biopsies were originally reported as negative or indeterminate for malignancy. On the basis of immunohistochemical stains for intestinal (MUC2, CD10, and CDX-2) and gastric (MUC5AC and MUC6) markers, 11 (52\%) cases had an intestinal immunophenotype and 10 $(48 \%)$ cases had a mixed immunophenotype. Foci of discohesive neoplastic cells, indicating dedifferentiation toward a poorly cohesive carcinoma, were observed exclusively in neoplasms of mixed immunophenotype $(n=5)$. All patients with follow-up but one were alive without disease at a mean of 19 months (range 1-60 months). One individual with a pT4 tumor with associated poorly cohesive carcinoma died of disease. In summary, very well-differentiated gastric adenocarcinomas are diagnostically challenging. Architectural features are critical to making the diagnosis. Cases with pure intestinal immunophenotype have not been associated with transformation into poorly cohesive carcinoma, and appear to behave as biologically low grade. Those with mixed immunophenotype appear more likely to dedifferentiate and behave more aggressively. Modern Pathology (2013) 26, 1620-1631; doi:10.1038/modpathol.2013.98; published online 31 May 2013
\end{abstract}

Keywords: gastric cancer; immunophenotype; very well differentiated

Very well-differentiated gastric adenocarcinoma of intestinal type is a distinct variant characterized by low-grade nuclear atypia and a morphology mimicking intestinal metaplasia. ${ }^{1-3}$ The neoplastic glands show subtle architectural abnormalities such as branching and anastomosis, commonly reproducing the shapes of the letters $\mathrm{W}, \mathrm{H}, \mathrm{Y}$, or $\mathrm{X}$ at low power. ${ }^{4}$ Anecdotally, we have noted the challenge in diagnosing this variant of gastric adenocarcinoma, especially on biopsy specimens, which are often misinterpreted as reactive intestinal metaplasia.

Correspondence: $\mathrm{Dr} \mathrm{T}$ Ushiku, $\mathrm{MD}, \mathrm{PhD}$, Department of Pathology, University of Tokyo, 7-3-1 Hongo, Bunkyo-ku, Tokyo 113-0033, Japan.

E-mail: usikut-tky@umin.ac.jp

Received 12 February 2013; revised 5 April 2013; accepted 28 April 2013; published online 31 May 2013
Endoscopically, this type of gastric cancer frequently presents as an ill-defined lesion with an indistinct border and a slightly depressed or flat appearance without marked mucosal tinctorial alteration. ${ }^{5}$ Notoriously, the subtle endoscopic findings make the diagnosis of this lesion just as challenging for the endoscopist. ${ }^{5}$ Although it has been suggested that very well-differentiated gastric adenocarcinomas have low malignant potential with slow growth, some cases have been reported with transformation into diffuse-type morphology resulting in more aggressive behavior. ${ }^{1-3,6}$ As a matter of fact, the spectrum of this variant of gastric adenocarcinoma, including its clinicopathological features and biological behavior, has not been well characterized because this entity is rare, noted to comprise only $1.9 \%$ of early gastric cancer, and it has been described in only a few small series. ${ }^{1-3,5}$ 
Given the limited information available to date, we initiated this study to evaluate a series of very well-differentiated gastric adenocarcinomas of intestinal type in detail, with a notable focus on determining the key diagnostic features of this challenging lesion. We also investigated the biological behavior by reviewing the clinical course in this cohort of patients.

\section{Materials and methods}

\section{Case Selection}

We identified a series of 21 very well-differentiated gastric adenocarcinomas of intestinal metaplasia type obtained from the pathology archives of the authors' institutions and from the consultation files of two of the authors (SB and MF). All cases met the criteria put forward previously. ${ }^{1,5}$ In brief, very welldifferentiated gastric adenocarcinomas of intestinal type are composed of neoplastic epithelium with low-grade nuclear atypia, differentiating toward metaplastic intestinal type cells, such as absorptive cells, goblet cells, Paneth cells, and of simple tall mucin-producing cells akin to foveolar-type epithelia. Architecturally, glandular structures are commonly seen with tortuousness, branching, or anastomosing, recapitulating the shapes of the letters W, H, Y, or X at low-power view. Characteristically, the neoplastic glands are usually sparsely distributed and lack back-to-back crowding. All 21 cases were reviewed by four pathologists to confirm the diagnosis of very well-differentiated adenocarcinoma of intestinal type.

The study was approved by the Institutional Review Board of the Massachusetts General Hospital.

\section{Clinical Data}

Demographic data, endoscopic findings, and clinical follow-up were obtained by review of the medical records. The macroscopic type of tumor was classified according to the criteria in the World Health Organization classification for early gastric cancer and the Borrmann classification for advanced gastric cancer. ${ }^{7}$

\section{Histologic Assessment}

Hematoxylin and eosin-stained sections were available in all cases and were evaluated for size of the lesion, depth of invasion, lymphovascular invasion, and lymph node metastasis in the 11 cases surgically resected. The presence or absence of a set of architectural, nuclear, cytomorphologic, and stromal features in each case were systematically recorded according to the consensus opinion of two study pathologists using a multiheaded microscope. Independent reviews of the cases for the diagnostic criteria were not performed and consequently interobserver variability in the assessment of these features was not determined. The architectural features that were assessed included tortuosity, branching, anastomosing, distention, abortive and spiky glandular patterns, glandular outgrowth, and discohesive neoplastic cells. Branching glands were defined as structures dividing downward, and typically demonstrating an inverted Y-shaped pattern, whereas anastomosing glands were laterally connected (H- or X-shaped) or fused downward (W- or Y-shaped). A spiky gland was defined as a glandular structure with sharp edges or sharp projections (Figure 1). Glandular outgrowth was defined as the presence of a very small glandular structure emerging from a larger gland (Figure 1).

Cytomorphologic features that were evaluated included the presence of normal and dystrophic goblet cells, foveolar epithelium, absorptive cells, and Paneth cells. We also assessed the presence of altered nuclear features: nuclear enlargement, hyperchromasia, clearing of chromatin, prominent nucleoli, mitotic rate, and presence of atypical mitoses. Finally, stromal features were reviewed, such as quality of the lamina propria, that is, myxoid change, stromal edema, desmoplasia, inflammation, and vascular ectasia. For cases with submucosal or advanced invasion, mucosal and deeper invasive components were evaluated separately.

Each feature was recorded semiquantitatively by evaluating the proportion of the involved area over the entire lesion as follows: absent; $1+$ (present in $<25 \%$ of lesion), $2+$ (present in $25-50 \%$ of lesion), and $3+$ (present in $>50 \%$ of lesion).

\section{Immunohistochemical Analysis}

Formalin-fixed paraffin-embedded tissue blocks were available in all 21 cases. To determine the tumor phenotype, immunohistochemical staining was performed using antibodies for MUC2 (CLH2, 1:500, Novocastra Laboratories, Newcastle, UK), CD10 (56C6, 1:100, Novocastra Laboratories), CDX-2 (CDX-2-88, 1:100, Biogenex, San Ramon, CA), MUC5AC (CLH5, 1:500, Novocastra Laboratories), and MUC6 (Ccp58, 1:500, Novocastra Laboratories). In brief, $5 \mu \mathrm{m}$ sections were deparaffinized and hydrated through a graded series of alcohol. Following antigen retrieval in $10 \mathrm{mM}$ citrate buffer ( $\mathrm{pH}$ 6.0) in a microwave oven for $10 \mathrm{~min}$, inhibition of endogenous peroxidase activity was performed by immersion in a $3 \% \mathrm{H}_{2} \mathrm{O}_{2} /$ methanol solution. The sections were then incubated with the primary antibodies, thoroughly washed in phosphate-buffered solution, and incubated with a biotinylated secondary antibody, followed by treatment with the avidin-biotinylated horseradish peroxidase complex (Vectastain Elite ABC kit, Vector Laboratories, Burlingame, CA). The sections were developed using DAB (3,3-diaminobenzidinetetrachloride) as the chromogen. Nuclear counterstaining was accomplished using Mayer's hematoxylin.

Cytoplasmic staining for mucin core proteins and apical membranous staining for CD10 were evaluated. For CDX-2, only nuclear staining was 

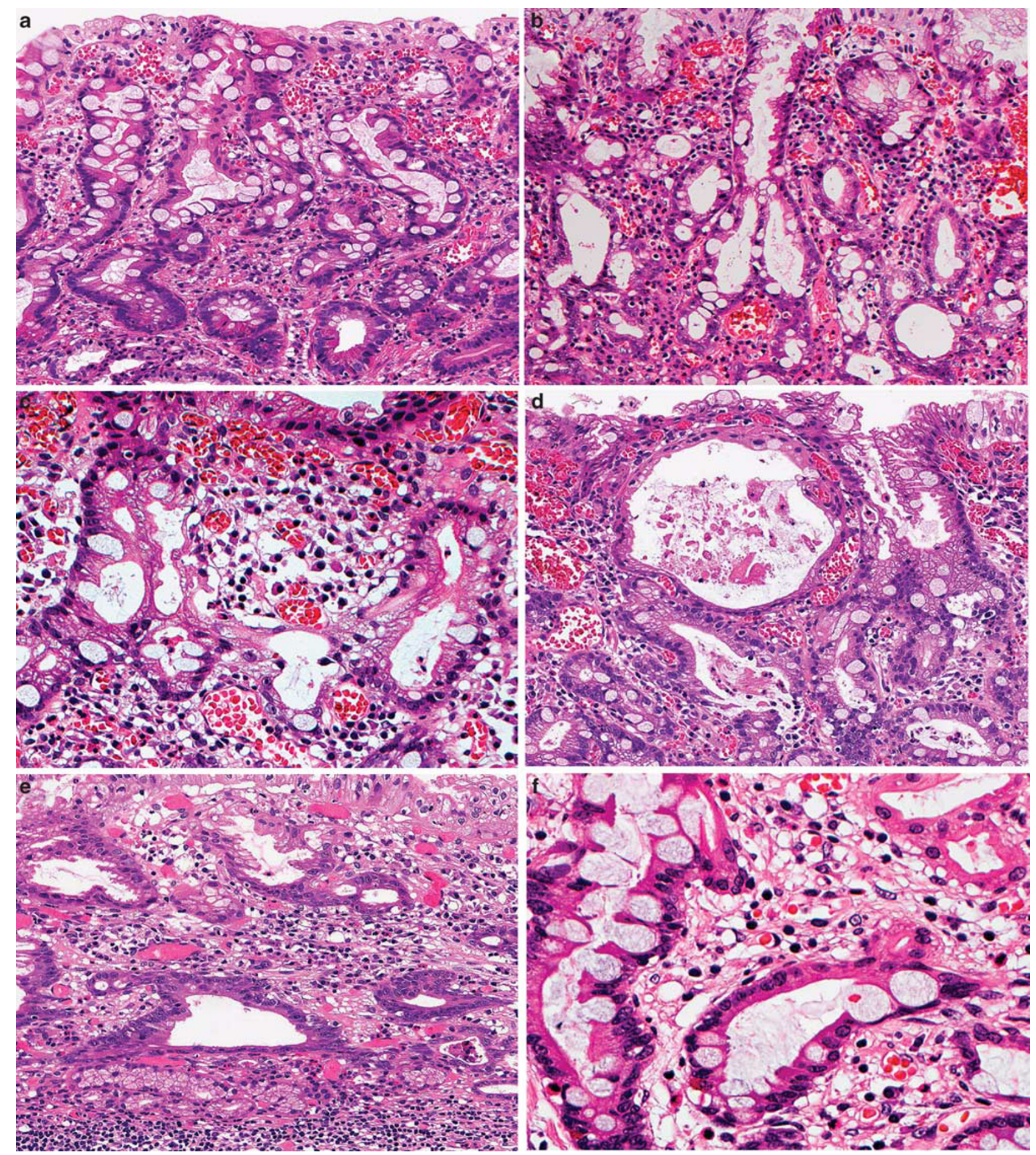

Figure 1 Representative examples of tortuous glands (a), a branching gland (b), anastomosing glands (c), a distended gland (d), spiky glands (e), and glandular outgrowth (f) in very well-differentiated adenocarcinoma of intestinal type.

considered positive. The tumor was defined as positive for each marker when $>10 \%$ of the neoplastic cells were stained. Tumors were categorized into gastric or intestinal phenotypes if they were positive for gastric (MUC5AC or MUC6) or intestinal (MUC2, CD10 or CDX-2) markers, respectively. Tumors were classified as mixed type when both gastric and intestinal markers were positive, and tumors were classified as null type when both markers were negative. ${ }^{8}$

\section{Evaluation of Pre-Resection Biopsies}

Pretreatment biopsy specimens were available in 18 patients. Whether the very well-differentiated 
gastric adenocarcinoma was present in each biopsy was evaluated by comparing the biopsies with the corresponding resection specimens. We evaluated each diagnostic biopsy for the cytoarchitectural features described above. The time interval between the initial biopsy and resection, the number of endoscopic procedures performed, the total number of biopsy fragments, and the original diagnosis for each biopsy were also recorded.

\section{Statistical Analysis}

Continuous variables were compared using the Student's $t$-test and categorical variables were compared using Fisher's exact test or $\chi^{2}$ - test (Excel Statistics, SSRI, Tokyo, Japan). Differences were considered to be significant if the $P$-value from the two-tailed test was $<0.05$.

\section{Results}

\section{Clinicopathologic Features}

The characteristics of the 21 cases are summarized in Table 1. The patients ranged in age from 53 to 84 years (mean, 67 years; median, 68 years) with a male to female ratio of 2:1 (14:7). Most cases were identified within the middle-third of the stomach (15 of $21,71 \%$ ), and the remaining six were equally distributed in the upper- and lower-third of the stomach. Tumor size ranged from 0.3 to $19 \mathrm{~cm}$ (mean, $3.2 \mathrm{~cm}$; median, $1.5 \mathrm{~cm}$ ). Endoscopically, all early cancers had the appearance of a predominantly superficial depressed lesion $(n=17)$, except for one showing a superficial elevated lesion (Figure 2). The borders were ill-defined in 9 of 18 cases $(50 \%)$, and 4 tumors $(22 \%)$ were accompanied by submucosal fibrosis. Of the advanced cancers, two presented as Borrmann's type-4 lesions, demonstrating an irregular or flat surface with marked mural thickening, while one tumor formed a plateau-like elevated lesion (type 1). Endoscopic resections were performed in 12 cases, and 9 tumors were surgically resected. In addition, secondary surgical resection was performed in two cases (cases 11 and 12) when the resection margins returned positive after endoscopic resection.

Histologically, $86 \%$ of tumors $(n=18)$ were early cancers, including 17 intramucosal cancers (pT1a) and 1 with superficial submucosal invasion (pT1b). The remaining three cases were advanced, all of

Table 1 Clinicopathologic findings of 21 very well-differentiated adenocarcinomas of intestinal type

\begin{tabular}{|c|c|c|c|c|c|c|c|c|c|c|}
\hline Case & $\begin{array}{c}\text { Age } \\
\text { (years) }\end{array}$ & Sex & $\begin{array}{c}\text { Tumor size, } \\
\text { greatest } \\
\text { dimension }(\mathrm{mm})\end{array}$ & Location $^{\mathrm{a}}$ & $\begin{array}{l}\text { Macroscopic } \\
\text { finding }\end{array}$ & $p T / N$ & $\begin{array}{c}\text { Lymphovascular } \\
\text { invasion }\end{array}$ & Treatment & $\begin{array}{l}\text { Follow-up } \\
\text { (months) }\end{array}$ & Status \\
\hline 1 & 60 & Female & 10 & $\mathrm{M}$ & IIc & pT1a/N0 & 0 & Endoscopy ${ }^{\mathrm{C}}$ & 10 & AWD \\
\hline 2 & 59 & Male & 5 & $\mathrm{M}$ & III & $\mathrm{pT} 1 \mathrm{a} / \mathrm{No}$ & 0 & Endoscopy ${ }^{\mathrm{C}}$ & 13 & AWD \\
\hline 3 & 71 & Male & 15 & $\mathrm{M}$ & $\begin{array}{l}\text { IIa + IIb (ill } \\
\text { defined) }\end{array}$ & $\mathrm{pT} 1 \mathrm{a} / \mathrm{N} 0$ & 0 & Endoscopy & 56 & AWD \\
\hline 4 & 75 & Female & 15 & $\mathrm{M}$ & IIc (ill defined) & $\mathrm{pT} 1 \mathrm{a} / \mathrm{N0}$ & 0 & Endoscopy ${ }^{\mathrm{C}}$ & 2 & AWD \\
\hline 5 & 63 & Female & 23 & $\mathrm{M}$ & IIc & $\mathrm{pT} 1 \mathrm{a} / \mathrm{N} 0$ & 0 & Endoscopy ${ }^{\mathrm{C}}$ & 6 & AWD \\
\hline 6 & 76 & Female & 7 & $\mathrm{M}$ & IIc & $\mathrm{pT} 1 \mathrm{a} / \mathrm{N} 0$ & 0 & Endoscopy ${ }^{\mathrm{C}}$ & 4 & AWD \\
\hline 7 & 78 & Male & 11 & $\mathrm{M}$ & IIc (ill defined) & pT1a/No & 0 & Endoscopy ${ }^{\mathrm{C}}$ & 3 & AWD \\
\hline 8 & 72 & Male & 12 & $\mathrm{M}$ & IIc (ill defined) & pT1a/No & 0 & Endoscopy ${ }^{\mathrm{C}}$ & 1 & AWD \\
\hline 9 & 68 & Male & 22 & $\mathrm{M}$ & IIc & pT1a/No & 0 & Endoscopy ${ }^{\mathrm{C}}$ & NA & - \\
\hline 10 & 84 & Female & 11 & $\mathrm{M}$ & IIc & pT1a/No & 0 & Endoscopy ${ }^{\mathrm{d}}$ & NA & - \\
\hline 11 & 53 & Male & 66 & $\mathrm{M}$ & IIc (ill defined) & $\mathrm{pT} 1 \mathrm{a} / \mathrm{N} 0$ & 0 & Surgery $^{\mathrm{e}}$ & 36 & AWD \\
\hline 12 & 63 & Male & 32 & $\mathrm{U}$ & $\begin{array}{l}\text { IIc + IIb (ill } \\
\text { defined) }\end{array}$ & $\mathrm{pT} 1 \mathrm{a} / \mathrm{N} 0$ & 0 & Surgery & 3 & AWD \\
\hline 13 & 74 & Male & 12 & $\mathrm{M}$ & IIc (ill defined) & pT1a/No & 0 & Surgery ${ }^{\mathrm{f}}$ & 4 & AWD \\
\hline 14 & 61 & Female & 30 & $\mathrm{~L}$ & IIc (ill defined) & $\mathrm{pT} 1 \mathrm{a} / \mathrm{N} 0$ & 0 & Surgery ${ }^{f}$ & 1 & AWD \\
\hline 15 & 71 & Male & 3 & $\mathrm{M}$ & IIc & $\mathrm{pT} 1 \mathrm{a} / \mathrm{N} 0$ & 0 & Surgeryg & 41 & AWD \\
\hline 16 & 61 & Female & 13 & $\mathrm{M}$ & IIc & $\mathrm{pT} 1 \mathrm{a} / \mathrm{N} 0$ & 0 & Surgery ${ }^{\mathrm{f}}$ & 20 & AWD \\
\hline 17 & 53 & Male & 25 & $\mathrm{~L}$ & IIc & pT1a/No & 0 & Surgery $\mathrm{f}$ & NA & - \\
\hline 18 & 62 & Male & 30 & $\mathrm{M}$ & $\begin{array}{l}\text { IIc }+ \text { IIa }+ \text { IIb } \\
\text { (ill defined) }\end{array}$ & $\mathrm{pT} 1 \mathrm{~b} / \mathrm{No}$ & 0 & Surgeryg & NA & - \\
\hline 19 & 69 & Male & 80 & $\mathrm{~L}$ & Borrmann type 4 & pT4a/No & + & Surgeryg & 42 & Alive \\
\hline 20 & 66 & Male & 50 & $\mathrm{U}$ & Borrmann type 1 & $\mathrm{pT} 4 \mathrm{a} / \mathrm{No}$ & + & Surgeryg & 60 & AWD \\
\hline 21 & 68 & Male & 190 & $\mathrm{U}$ & Borrmann type 4 & $\mathrm{pT} 4 \mathrm{a} / \mathrm{N}+$ & + & Surgeryg & 27 & DOD \\
\hline
\end{tabular}

AWD, alive without disease; NA, not available; alive, alive without information of disease status; DOD, died of disease.

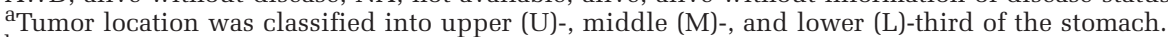

${ }^{b}$ Macroscopic finding was classified according to World Health Organization criteria. ${ }^{7}$

${ }^{\mathrm{C}}$ Endoscopy, endoscopic submucosal dissection.

$\mathrm{d}_{\text {Endoscopy, endoscopic mucosal resection. }}$

esurgery, total gastrectomy following endoscopic submucosal dissection because of positive margin.

f Surgery, distal gastrectomy.

g Surgery, total gastrectomy. 

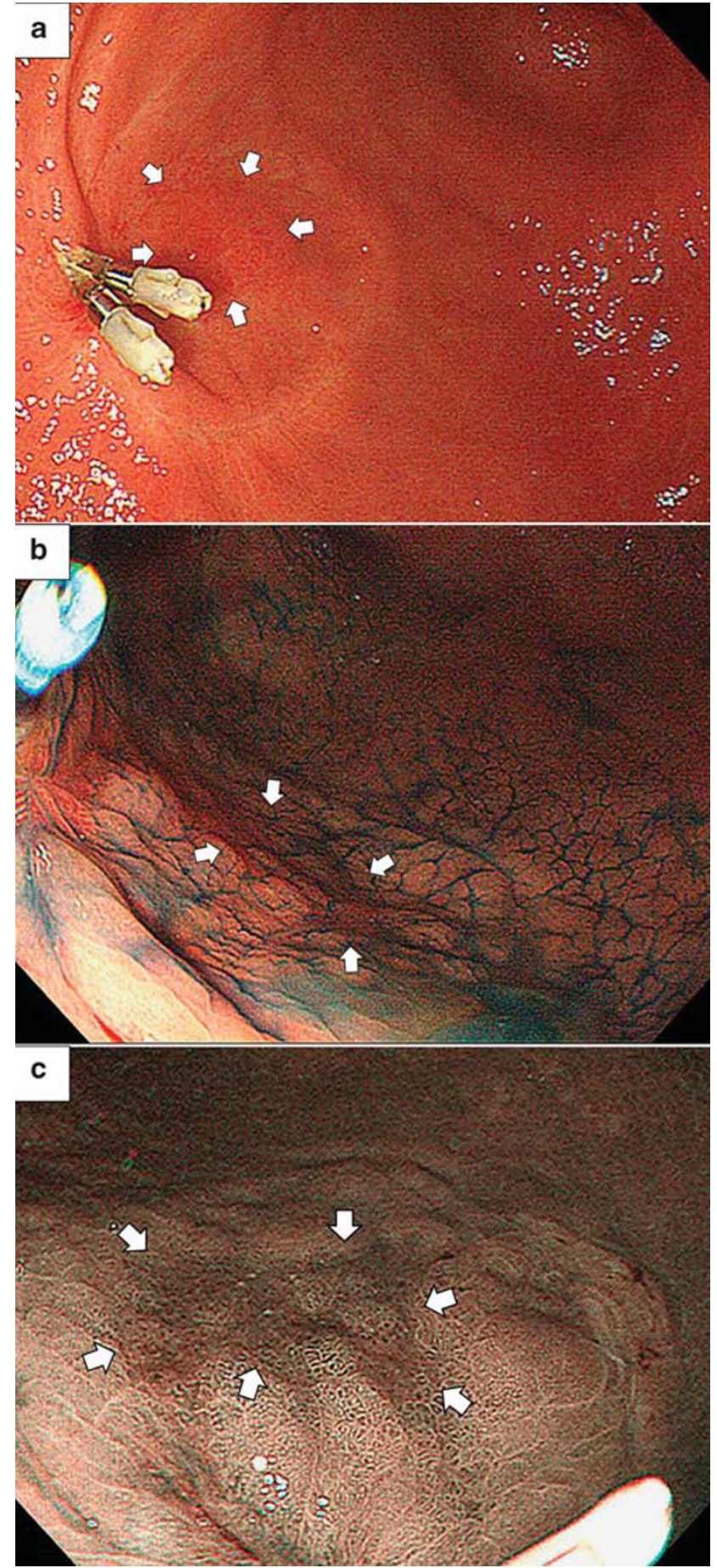

Figure 2 Endoscopic pictures of a very well-differentiated adenocarcinoma of intestinal type (case 5). Endoscopic examination demonstrates a superficial depressed erythematous lesion with an ill-defined margin using conventional endoscopic technique (a). Chromoendoscopy (b) and narrow-band imaging (c) better define the lesion.

which involved the serosal surface (pT4a). None of the 18 early cancers showed lymphovascular invasion, whereas it was present in all 3 advanced cancers. Nodal metastases were noted in only one of the advanced cancers (case 21).
Table 2 Cytoarchitectural and stromal findings in 17 intramucosal very well-differentiated adenocarcinomas of intestinal type

\begin{tabular}{|c|c|c|c|c|}
\hline Findings & Absent & $\begin{array}{c}1+ \\
(<25 \%)\end{array}$ & $\begin{array}{c}2+ \\
(26-50 \%)\end{array}$ & $\begin{array}{c}3+ \\
(>50 \%)\end{array}$ \\
\hline \multicolumn{5}{|l|}{ Architectural features } \\
\hline Tortuous glands & 0 & $1(6)$ & $16(94)$ & 0 \\
\hline Branching glands & 0 & $3(18)$ & $14(82)$ & 0 \\
\hline Anastomosing glands & 0 & $6(35)$ & $11(65)$ & 0 \\
\hline Distended glands & $2(12)$ & $8(47)$ & $7(41)$ & 0 \\
\hline Abortive glands & $2(12)$ & $12(71)$ & 3 (18) & 0 \\
\hline Spiky glands & $5(29)$ & $12(71)$ & 0 & 0 \\
\hline Glandular outgrowth & $4(24)$ & $12(71)$ & $1(6)$ & 0 \\
\hline Discohesive cells & $13(76)$ & $4(24)$ & 0 & 0 \\
\hline \multicolumn{5}{|l|}{ Cytomorphologic features } \\
\hline Normal goblet cells & 0 & $8(47)$ & $9(53)$ & 0 \\
\hline Foveolar epithelium & $13(76)$ & $4(24)$ & 0 & 0 \\
\hline Absorptive cells & 0 & 0 & $15(88)$ & $2(12)$ \\
\hline Paneth cells & $8(47)$ & $9(53)$ & 0 & 0 \\
\hline Dystrophic goblet cells & 0 & $10(59)$ & $7(41)$ & 0 \\
\hline \multicolumn{5}{|l|}{ Nuclear features } \\
\hline Enlarged nuclei & 0 & $1(6)$ & $10(59)$ & $6(35)$ \\
\hline Hyperchromasia & $7(41)$ & 0 & $6(35)$ & $4(24)$ \\
\hline Clearing of chromatin & $10(59)$ & $1(6)$ & $4(24)$ & $2(12)$ \\
\hline Prominent nucleoli & $8(47)$ & $1(6)$ & $7(41)$ & $1(6)$ \\
\hline Mitosis $^{\mathrm{a}}$ & 0 & $8(47)$ & $6(35)$ & $3(18)$ \\
\hline \multicolumn{5}{|l|}{ Stromal features } \\
\hline Normal lamina propria & $15(88)$ & 0 & $1(6)$ & $1(6)$ \\
\hline Myxoid change & $17(100)$ & 0 & 0 & 0 \\
\hline Stromal edema & $13(76)$ & 0 & $4(24)$ & 0 \\
\hline Desmoplasia & $16(94)$ & 0 & $1(6)$ & 0 \\
\hline Dense Inflammation & $1(6)$ & $2(12)$ & $12(71)$ & $2(12)$ \\
\hline Vascular ectasia & $7(41)$ & $6(35)$ & $4(24)$ & 0 \\
\hline
\end{tabular}

${ }^{\mathrm{a}}$ Mitosis count was scored as follows: $1+, 1-5 ; 2+, 6-10 ; 3+,>10$ per $10 \mathrm{HPF}$

Follow-up information was available in 17 cases (81\%), ranging from 1 to 60 months (mean, 19 months). One patient (case 21), who had a pT4 tumor with nodal metastases, died of disease at 27 months postoperatively. The others were alive without disease at last contact $(n=15)$ or alive without information about the disease status $(n=1)$.

\section{Assessment of a Series of Histologic Features}

Intramucosal very well-differentiated adenocarcinomas. Table 2 shows the histologic features observed in the 17 intramucosal cases. Tortuous, branching, and anastomosing glands were the predominant architectural patterns, and were observed to various degrees in all cases. Most cases also demonstrated distended glands (15 of 17, 88\%), abortive glands (15 of 17, 88\%), glandular outgrowth (13 of $17,76 \%$ ), and spiky glands (12 of $17,71 \%$ ). Discohesive neoplastic cells were focally present in four $(24 \%)$ cases.

The distorted neoplastic glands were composed of absorptive cells with a mixture of scattered normal and dystrophic goblet cells, whereas some cases also 


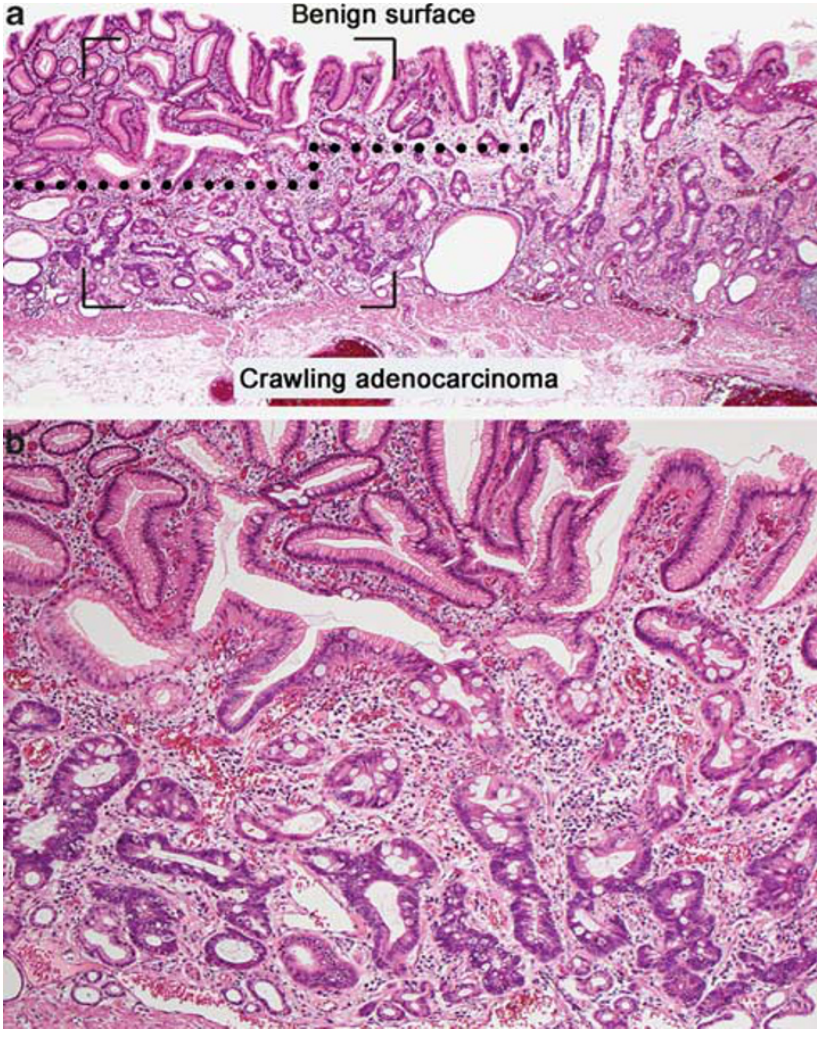

Figure 3 Low-power (a) and high-power (b, square frame in a) examples of a very well-differentiated adenocarcinoma with a 'crawling' pattern of intramucosal spread. The malignant glands infiltrate the lower half of the lamina propria (below the dotted line), extending laterally beneath the non-neoplastic surface epithelium (above the dotted line).

had Paneth cells (9 of 17, 53\%) and foveolar epithelium (4 of 17, 24\%). Nuclear atypia was minimal. Nuclear enlargement was observed in all cases but was mild in degree. Nuclear hyperchromasia (10 of 17, 59\%), prominent nucleoli (9 of 17, $53 \%$ ), and clearing of chromatin (7 of 17, 41\%) were also observed to various extents. Mitotic counts were 1-5 per 10 high-power fields (HPF) in eight (47\%), 6-10 per $10 \mathrm{HPF}$ in six (35\%), and > 10 (up to 12$)$ per $10 \mathrm{HPF}$ in three (18\%) cases. Atypical mitoses were absent. Most cases (16 of 17, 94\%) were accompanied by stromal lymphoplasmacytic inflammation in at least a portion of the lesion. The other stromal features included vascular ectasia (10 of $17,59 \%$ ), edema ( 4 of $17,24 \%$ ), and normal lamina propria ( 2 of $17,12 \%$ ). Only one case had a mild desmoplastic reaction focally.

In terms of growth pattern, 6 of 17 (35\%) cases demonstrated a peripheral 'crawling' pattern, that is, lateral tumoral spread in the middle or lower half of the lamina propria extending beneath the nonneoplastic epithelial surface (Figure 3). Four of the 17 cases showed clusters of discohesive neoplastic cells indicative of focal transformation into poorly cohesive carcinoma.
Submucosal or deeply invasive very well-differentiated gastric adenocarcinomas. The mucosal components of the four cases with submucosal or deeper involvement were relatively preserved in all cases, their features essentially similar to those cases limited to the mucosa. The degree of architectural atypia in two cases was in fact less severe than what was observed in the cases limited to the mucosa. Nuclear atypia was always mild, although nuclear enlargement, hyperchromasia, clearing of chromatin, and prominent nucleoli were observed to various degrees. Mitotic counts were 2-8 (mean, 4.8) per $10 \mathrm{HPFs}$ without a significant difference compared with intramucosal cancers. A 'crawling' pattern of the mucosal components was absent in all cases. Discohesive neoplastic cells were focally present in one of these cases (case 21).

The morphology of the submucosal or deeperinvasive component differed from that of the mucosal component in the three pT4a neoplasms (cases 19, 20, and 21), while there was minimal variation in the case limited to submucosal invasion (case 18). Two of the pT4 tumors (cases 19 and 20) retained the very well-differentiated morphology, but most submucosal neoplastic glands were larger than those observed in mucosa and often displayed cystic dilatation and contained eosinophilic debris and neutrophilic inflammation (Figure 4). In addition, a desmoplastic reaction and dense inflammation were observed at least focally. One case (case 21), which demonstrated discohesive neoplastic cells focally in the mucosa, presented a similar diffuse-type infiltrating pattern (poorly cohesive carcinoma) with desmoplastic response involving the full thickness of the stomach including the serosal surface (Figure 5).

Minimum number of architectural features in very well-differentiated adenocarcinoma. All 21 cases displayed a minimum of three of the following six architectural anomalies: anastomosing glands, spiky glands, distended glands, discohesive cells, abortive glands, and glandular outgrowth. Of these six features, three were present in 3 cases, four were present in 5 cases, five were present in 10 cases, and all six were present in 3 cases. In short, $86 \%$ of cases (18 of 21) had four or more of these architectural features.

\section{Immunophenotype and its Association with Clinicopathological Features}

All 21 neoplasms were positive for intestinal markers, including MUC2 (21 of 21), CDX-2 (19 of $21,90 \%$ ), and CD10 (18 of 21, 86\%). In addition, 10 of $21(48 \%)$ cases were positive for gastric markers with MUC5AC expressed in all cases and MUC6 in 9 of the 10 cases. On this basis, 11 (52\%) cases were classified as intestinal type (Figure 6) and 10 (48\%) cases as mixed type (Figure 7). In cases with 


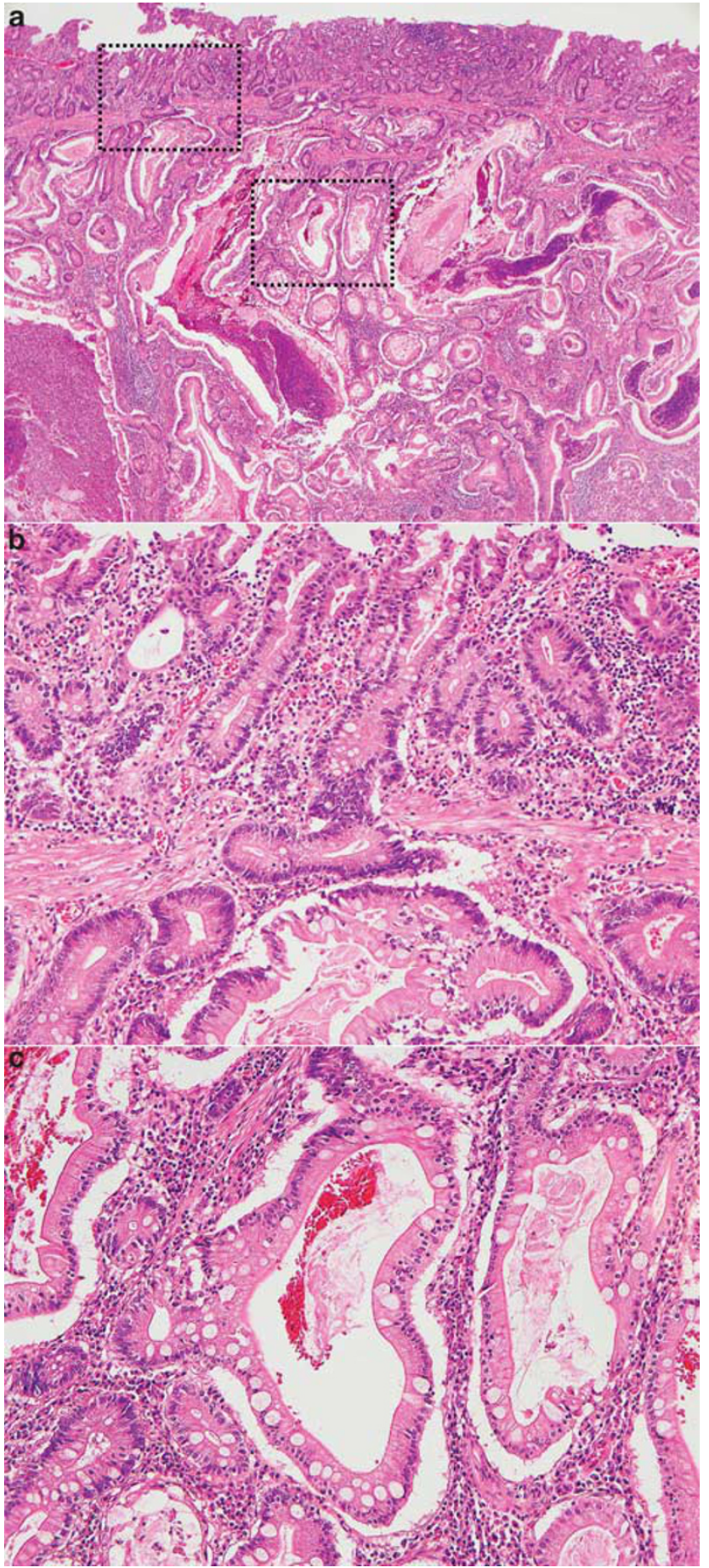

Figure 4 Case 20: low-power view (a) and higher magnification of mucosal (b, upper dotted frame in a) and deeply invasive area (c, lower dotted frame in a). This case retains very welldifferentiated morphology in the deeply invasive area, although the glandular structures are larger and more dilated compared with the intramucosal component.

submucosal or deeper invasion, the immunophenotype was preserved at all levels of the tumors except for case 21 , for which the deep-invasive component had a null phenotype.
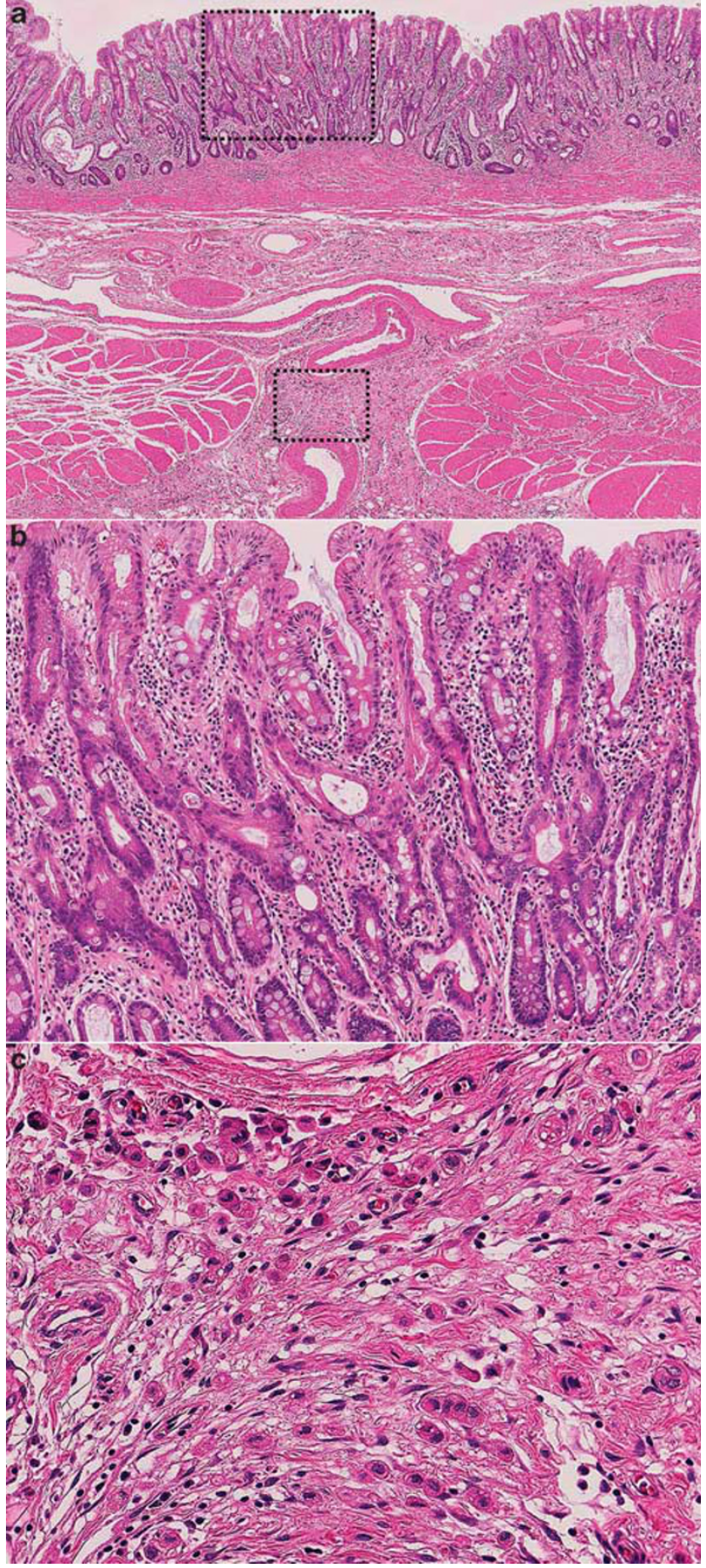

Figure 5 Case 21: low-power view (a) and higher magnification of mucosal (b, upper dotted frame in a) and deeply invasive area (c, lower dotted frame in a). In contrast to case 20 (Figure 4), this case demonstrates transformation from very well-differentiated adenocarcinoma (b) into poorly cohesive adenocarcinoma with desmoplastic reaction (c) involving the full thickness of the stomach.

No cases of intestinal phenotype had any discohesive neoplastic cells indicative of a poorly cohesive component, whereas 5 of $10(50 \%)$ cases of mixed phenotype were accompanied by at least 


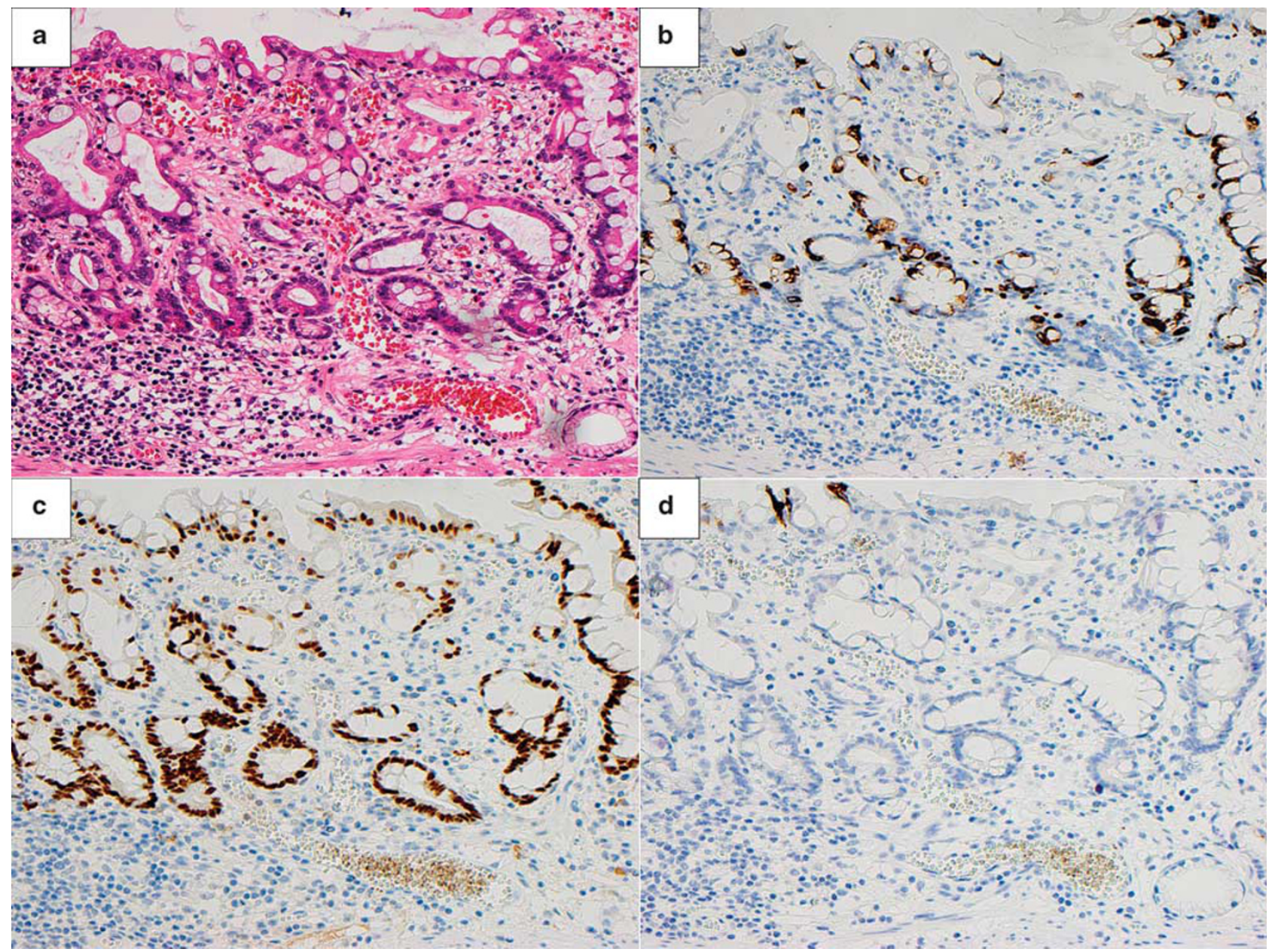

Figure 6 Very well-differentiated adenocarcinoma of intestinal immunophenotype (a, H\&E). Tumor cell are positive for MUC2 (b) and CDX-2 (c), but negative for MUC5AC (d).

focal poorly cohesive carcinoma. There was no significant difference between the two immunophenotypes in the other histologic features, such as, patient age, gender, tumor location, macroscopic type, and nodal status.

\section{Review of Pretreatment Endoscopic Biopsies}

One to eight pre-therapeutic endoscopic examinations were performed in 18 patients (median, 2; mean, 2.5). A total of 196 tissue biopsies were available for review. Retrospective review revealed that 84 of these original biopsies were already diagnostic for very well-differentiated adenocarcinoma. Yet, the original diagnoses were 'adenocarcinoma' or 'suspicious for adenocarcinoma' in only 30 and 12 biopsies (36\% and 14\%), respectively, whereas the original diagnoses in the others were 'indeterminate for neoplasia' or 'reactive intestinal metaplasia' in 22 and 20 biopsies (26\% and $24 \%$ ), respectively. Of the cytoarchitectural features previously discussed, discohesive neoplastic cells and spiky glands were seen in $24 \%$ and $62 \%$ of the cases, respectively, and were significantly associated with a diagnosis of 'adenocarcinoma' or 'suspicious for adenocarcinoma' compared with the other diagnoses of 'indeterminate for neoplasia' or 'reactive intestinal metaplasia,' in which they were observed in only $4 \%$ for discohesive neoplastic cells and $33 \%$ for spiky glands, respectively. However, there was no significant difference in the other histologic characteristics between the two groups.

The delay in diagnosis was usually less than a few months: <1 month in 13 cases (72\%), 1.5 months in 1 case $(6 \%)$, and 3 months in 1 case $(6 \%)$. However, in three cases $(17 \%)$ more than a year elapsed: 23 , 50, and 84 months. Endoscopically, these three lesions were ill defined and of small size, ranging from 1.2 to $1.5 \mathrm{~cm}$ in greatest dimension (Figure 8a and b). Notably, there were minimal changes in size between the first examination and resection in all the three cases. In addition, histologic evaluation of the resection specimen revealed that all three cases remained intramucosal cancers, and none had a 


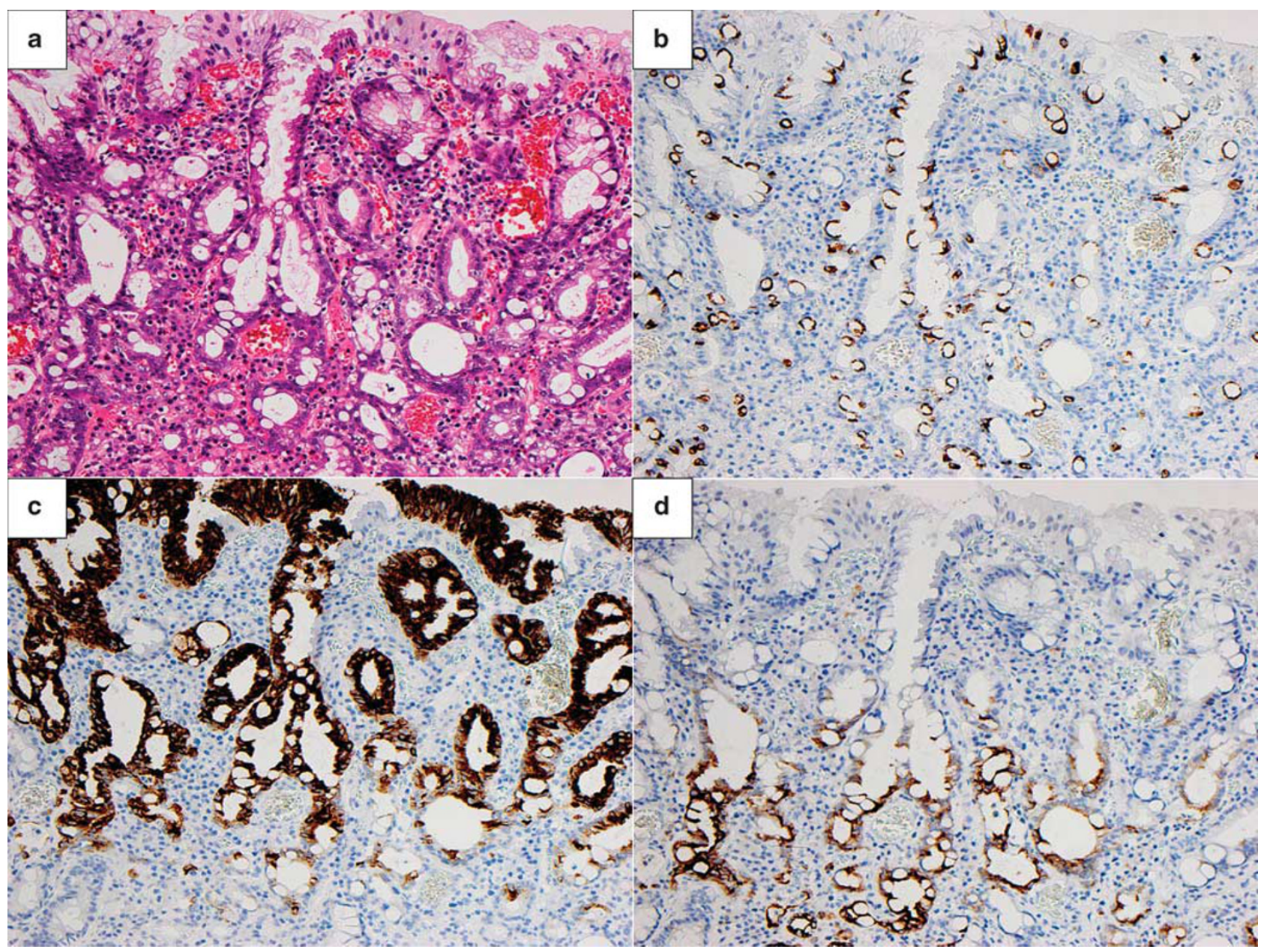

Figure 7 Very well-differentiated adenocarcinoma of mixed immunophenotype (a, H\&E). Tumor cells show positive staining for MUC2 (b), MUC5AC (c) and MUC6 (d).

poorly cohesive carcinoma component (Figure 8c and d). Table 3 summarizes the original pathologic diagnosis and endoscopic findings at resection of these three cases. On retrospective review, every set of biopsies from the three cases presented in Table 3 did contain tissue that was diagnostic for very well-differentiated adenocarcinoma.

\section{Discussion}

Very well-differentiated adenocarcinoma 'mimicking intestinal metaplasia' was described first by Endoh et $a l,{ }^{1}$ and later by Yao et $a l,{ }^{3}$ who reported nine additional examples of 'extremely welldifferentiated adenocarcinoma,' including gastric type $(n=5)$ and intestinal type $(n=4)$. Recently, Okamoto et $a l^{2}$ reported a large series of such cases $(n=25)$, emphasizing the characteristic lateral (crawling) spread pattern of these neoplasms. These previous studies reported some of the features that we assess here, including tortuous, branching, anastomosing, and distended glands, as well as the presence of discohesive cells. ${ }^{1-3}$ A limited set of stromal features including desmoplasia and inflammation have also been noted previously. ${ }^{3}$ The finding of 'spiky' glands, glandular outgrowth, and abortive glands as architectural features and the assessment of the remaining stromal features have not previously been described. Similarly, no prior study has systematically assessed the combined set of cytomorphologic features that we present in Table 2.

Although very well-differentiated gastric adenocarcinoma of intestinal type is well established in the Japanese literature, there is a possibility that western pathologists may view this diagnosis with skepticism because of the bland nuclear features and limited exposure owing to its extreme rarity. Consequently, the particular importance of this study is that it demonstrates that very well-differentiated adenocarcinoma, despite having minimal nuclear atypia, is an irrefutably malignant lesion, as evidenced by a number of cases with associated submucosal or transmural invasion and discohesive (signet-ring) cell transformation. 


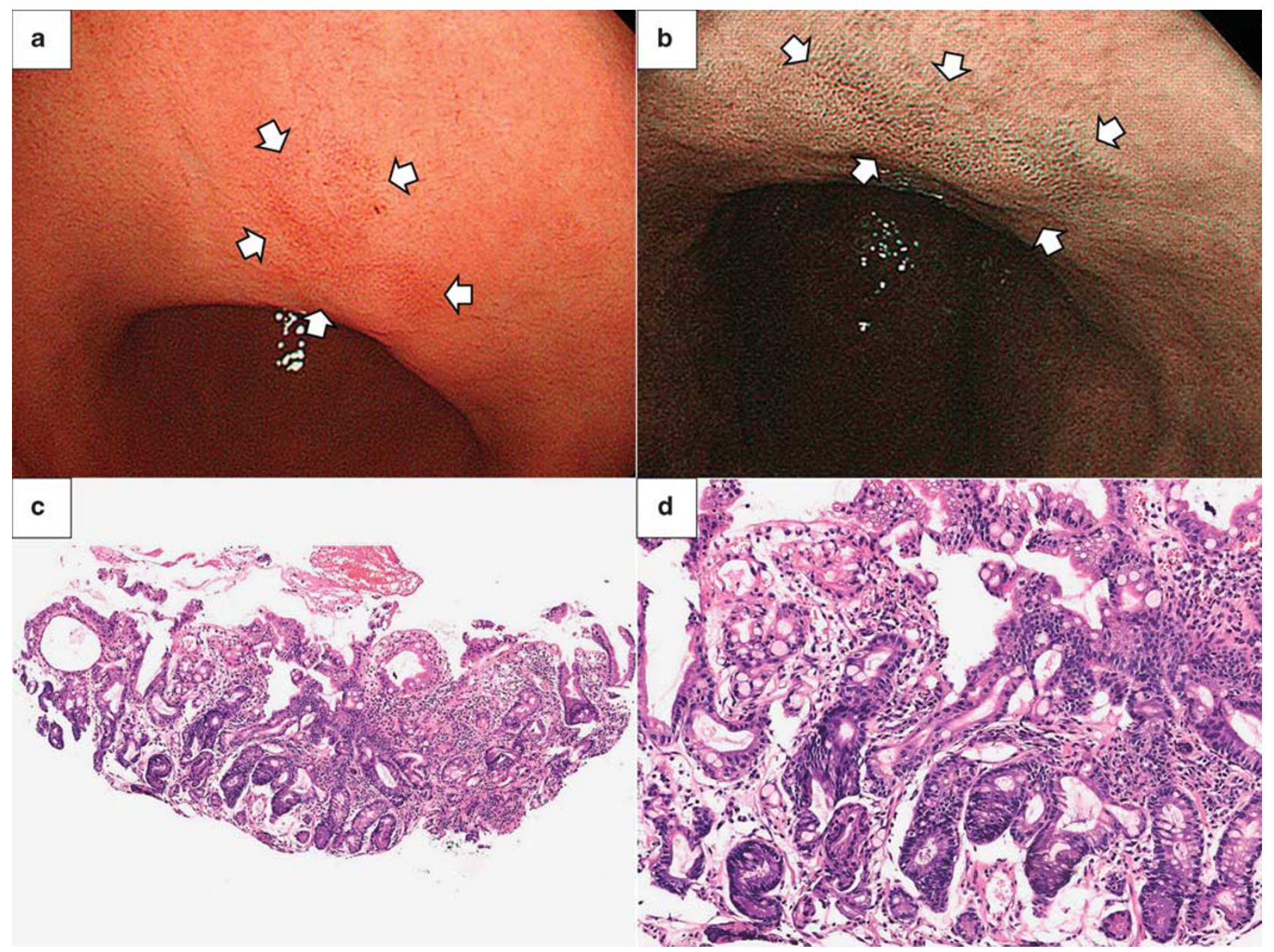

Figure 8 A case with a long-term follow-up before resection (case 4). An endoscopic picture just before resection demonstrates an ill-defined superficial depressed lesion (a). Narrow-band imaging highlights the lesion (b). The initial biopsy performed 23 months before resection (c). Although the original diagnosis was intestinal metaplasia with reactive change, retrospective review revealed that this biopsy was already diagnostic for very well-differentiated adenocarcinoma based on the aberrant branching, anastomosing, abortive glands, and glandular outgrowth (d).

Although very well-differentiated gastric adenocarcinoma is currently regarded a rare entity, it is likely that advances in endoscopic imaging, such as chromoendoscopy, magnifying endoscopy, and narrow-band imaging, and increased screening will increase the frequency of detection of this entity. ${ }^{9-11}$ Consequently, it is important for pathologists and endoscopists to be aware of this variant of gastric cancer. Our evaluation resulted in the recognition of a set of morphologic features that may serve as a useful diagnostic reference for pathologists faced with a possible case of very well-differentiated adenocarcinoma of intestinal type. We found architectural features to be most informative, and we determined that no less than three of the six architectural features (anastomosing glands, spiky glands, distended glands, discohesive cells, abortive glands, and glandular outgrowth) were present in all the cases. Adherence to these architectural criteria should prevent the overdiagnosis of very welldifferentiated adenocarcinoma. In difficult cases, re-biopsy or consultation with an expert gastrointestinal pathologist who has experience with this entity should be considered. Fortunately, failure to make the diagnosis of very well-differentiated adenocarcinoma on the first biopsy will generally have little consequence because the lesions are slow growing.

Endoscopically, intramucosal very well-differentiated adenocarcinomas are frequently ill defined with indistinct borders, a characteristic associated with higher rates of incomplete resection along the lateral margins when compared with other histologic types of gastric cancer. ${ }^{5}$ This seems to be partly due to the 'crawling' pattern of growth at the periphery that was indeed recognized in our series. We also showed that the endoscopic challenges are matched by histologic difficulties in establishing malignancy, with $50 \%$ of the original diagnostic biopsies incorrectly interpreted as either 'indeterminate for neoplasia' or 'reactive intestinal metaplasia.' Yet it is also important to stress that 
Table 3 Endoscopic findings and original biopsy diagnoses of three cases with long-term follow-up before resection

\begin{tabular}{|c|c|c|c|c|}
\hline Case & Endoscopic finding ${ }^{\mathrm{a}}$ & $\begin{array}{l}\text { Interval between first } \\
\text { biopsy and resection }\end{array}$ & $\begin{array}{l}\text { Endoscopic } \\
\text { procedures }\end{array}$ & $\begin{array}{l}\text { Original diagnoses for specimens } \\
\text { containing cancer }\end{array}$ \\
\hline 3 & $\begin{array}{l}\text { IIa }+ \text { IIb, ill defined } \\
1.5 \mathrm{~cm} \text { in size }\end{array}$ & 50 months & $\begin{array}{l}\# 1 \\
\# 2 \\
\# 3 \\
\# 4 \\
\# 5 \\
\# 6\end{array}$ & $\begin{array}{l}\text { Indefinite for neoplasia } \\
\text { Indefinite for neoplasia } \\
\text { Reactive intestinal metaplasia } \\
\text { Reactive intestinal metaplasia } \\
\text { Suspicious for adenocarcinoma } \\
\text { Suspicious for adenocarcinoma }\end{array}$ \\
\hline 4 & $\begin{array}{l}\text { IIc, ill defined } \\
1.5 \mathrm{~cm} \text { in size }\end{array}$ & 23 months & $\begin{array}{l}\# 1 \\
\# 2 \\
\# 3 \\
\# 4 \\
\# 5 \\
\# 6 \\
\# 7\end{array}$ & $\begin{array}{l}\text { Reactive intestinal metaplasia } \\
\text { Indefinite for neoplasia } \\
\text { Indefinite for neoplasia } \\
\text { Reactive intestinal metaplasia } \\
\text { Adenocarcinoma } \\
\text { Reactive intestinal metaplasia } \\
\text { Suspicious for adenocarcinoma }\end{array}$ \\
\hline 8 & $\begin{array}{l}\text { IIc, ill defined } \\
1.2 \mathrm{~cm} \text { in size }\end{array}$ & 84 months & $\begin{array}{l}\# 1 \\
\# 2 \\
\# 3 \\
\# 4 \\
\# 5 \\
\# 6 \\
\# 7 \\
\# 8\end{array}$ & $\begin{array}{l}\text { Indefinite for neoplasia } \\
\text { Reactive intestinal metaplasia } \\
\text { Indefinite for neoplasia } \\
\text { Reactive intestinal metaplasia } \\
\text { Reactive intestinal metaplasia } \\
\text { Suspicious for adenocarcinoma } \\
\text { Suspicious for adenocarcinoma } \\
\text { Suspicious for adenocarcinoma }\end{array}$ \\
\hline
\end{tabular}

On retrospective review, very well differentiated adenocarcinoma could be identified in each set of biopsies listed in this table.

${ }^{a}$ Macroscopic finding was classified according to World Health Organization criteria. ${ }^{7}$

Table 4 Clinicopathologic comparison between intestinal and mixed immunophenotype in cases reported here and in three previous studies $^{1-3}$

\begin{tabular}{|c|c|c|c|}
\hline Findings & Intestinal immunophenotype $(\mathrm{n}=23)$ & Mixed immunophenotype $(\mathrm{n}=35)$ & $\mathrm{P}$-value \\
\hline \multicolumn{4}{|l|}{ Sex } \\
\hline Male & 16 & 27 & 0.76 \\
\hline Female & 7 & 8 & \\
\hline Age, years & 45-76 (mean, 65) & 40-84 (mean, 62) & 0.39 \\
\hline \multicolumn{4}{|l|}{ Locus } \\
\hline $\mathrm{U} / \mathrm{M} / \mathrm{L}^{\mathrm{a}}$ & $1 / 20 / 2$ & $4 / 25 / 6$ & 0.38 \\
\hline $\mathrm{pT} 1 \mathrm{a} / 1 \mathrm{~b} / 2 / 3 / 4$ & $8 / 10 / 2 / 0 / 3$ & $25 / 9 / 0 / 0 / 1$ & 0.021 \\
\hline \multicolumn{4}{|l|}{ Macroscopic type } \\
\hline Elevated & 11 & 0 & $<0.0001$ \\
\hline Depressed or flat & 12 & 35 & \\
\hline \multicolumn{4}{|l|}{ Discohesive cells } \\
\hline Present & 0 & 24 & $<0.0001$ \\
\hline Absent & 23 & 11 & \\
\hline \multicolumn{4}{|l|}{ Nodal metastasis } \\
\hline Present & 0 & 5 & 0.059 \\
\hline Absent & 23 & 24 & \\
\hline \multicolumn{4}{|l|}{ beyond (if present) } \\
\hline Very well-differentiated adenocarcinoma & 15 & 0 & $<0.0001$ \\
\hline Poorly cohesive type & 0 & 10 & \\
\hline
\end{tabular}

${ }^{\mathrm{a}}$ Tumor location was classified into upper (U), middle (M), and lower (L) third of the stomach.

despite the delay in diagnosis, extending over 1 year in a non-negligible $17 \%$ of our cases, only limited progression was noted.
Immunophenotypically, $48 \%$ of the tumors had a mixed phenotype and $52 \%$ presented an intestinal immunophenotype. Very well-differentiated 
adenocarcinomas with mixed immunophenotype appear to preserve a low-grade malignancy profile as long as discohesive neoplastic cells are absent. In our series, the five intramucosal cancers falling into that category remained without nodal metastasis. However, it is noteworthy that all of the cases in which discohesive neoplastic cells were detected presented a mixed phenotype, suggesting a heightened risk of transformation specific to this subgroup which then acquires a more aggressive behavior.

Interestingly, comparing this observation with the three previous series that included immunophenotypic analysis $(n=58$ in total, including our cases) $)^{1-3}$ (Table 4), it appears that a poorly cohesive carcinoma component was present in $69 \%$ of the cases with mixed phenotype, but was absent in all cases of intestinal phenotype $(P<0.0001)$. This observation confirms our inference. Finally, nodal metastases were present in 5 of these 58 cases, all of which showed mixed phenotype tumors with poorly cohesive carcinoma components.

On the contrary, those cases of intestinal immunophenotype had less aggressive biological behavior, were not accompanied by a focal component of poorly cohesive carcinoma, and retained their well-differentiated morphology in submucosal and deeper-invasive areas. ${ }^{1-3}$ Furthermore, nodal metastases were absent and no fatal cases have been reported in this subgroup, even in pT4 tumors. As further evidence of its indolent behavior, two cases of pure intestinal phenotype in our series remained intramucosal without significant increase in size during a long-term preoperative follow-up (50 and 84 months). This observation is indirectly supported by the previous reports of a low Ki67 labeling index and a lack of p53 or c-erbB2 protein overexpression in this subtype. ${ }^{1,3}$

In summary, very well-differentiated gastric adenocarcinoma of intestinal type represents a diagnostic challenge, particularly on biopsy specimens. On the basis of our series, the histologic diagnosis is best established using a combination of at least three of the six architectural features, including anastomosing glands, spiky glands, distended glands, discohesive cells, abortive glands, and glandular outgrowth. However, a blinded sensitivity/specificity analysis of these criteria is an important focus for future research. This variant can be divided into two groups based on the immunophenotype. Those with an intestinal immunophenotype do not appear to be associated with a risk of development of poorly cohesive carcinoma, and appear to be indolent. Alternatively, those with mixed immunophenotype are not infrequently associated with a focus of discohesive neoplastic cells, and are more likely to present an aggressive behavior.

\section{Acknowledgements}

This work was partly supported by Grants-in-Aid for Young Scientists (B) 23790390 from The Ministry of Education, Culture, Sports, Science and Technology of Japan. Dr Arnason's fellowship funding was provided through scholarships from the Royal College of Physicians and Surgeons of Canada (Detweiler Traveling Fellowship) and Dalhousie University (McLoughlin Scholarship).

\section{Disclosure/conflict of interest}

The authors declare no conflict of interest.

\section{References}

1 Endoh Y, Tamura G, Motoyama T, et al. Welldifferentiated adenocarcinoma mimicking completetype intestinal metaplasia in the stomach. Hum Pathol 1999;30:826-832.

2 Okamoto N, Kawachi H, Yoshida T, et al. 'Crawlingtype' adenocarcinoma of the stomach: a distinct entity preceding poorly differentiated adenocarcinoma. Gastric Cancer 2013;16:220-232.

3 Yao T, Utsunomiya T, Oya M, et al. Extremely welldifferentiated adenocarcinoma of the stomach: clinicopathological and immunohistochemical features. World J Gastroenterol 2006;12:2510-2516.

4 Kato Y, Yanagisawa A, Sugano H. Biopsy interpretation in diagnosis of gastric carcinoma, In: Nishi M, Ichikawa H, Nakajima T, et al. (eds) Gastric Cancer. Springer: Tokyo, 1993, pp 133-150.

5 Kang KJ, Kim KM, Kim JJ, et al. Gastric extremely well-differentiated intestinal-type adenocarcinoma: a challenging lesion to achieve complete endoscopic resection. Endoscopy 2012;44:949-952.

6 Kushima R, Vieth M, Borchard F, et al. Gastric-type well-differentiated adenocarcinoma and pyloric gland adenoma of the stomach. Gastric Cancer 2006;9:177-184.

7 Bosman FT, Carneiro F, Hruban RH, et al. (eds) WHO Classification of Tumours of the Digestive System. IARC: Lyon; 2010, pp 48-51.

8 Tsukashita S, Kushima R, Bamba M, et al. MUC gene expression and histogenesis of adenocarcinoma of the stomach. Int J Cancer 2001;94:166-170.

9 Dinis-Ribeiro M. Chromoendoscopy for early diagnosis of gastric cancer. Eur J Gastroenterol Hepatol 2006;18: 831-838.

10 Nagahama T, Yao K, Maki S, et al. Usefulness of magnifying endoscopy with narrow-band imaging for determining the horizontal extent of early gastric cancer when there is an unclear margin by chromoendoscopy (with video). Gastrointest Endosc 2011;74: 1259-1267.

11 Nishi M, Ishihara S, Nakajima T, et al. Chronological changes of characteristics of early gastric cancer and therapy: experience in the Cancer Institute Hospital of Tokyo, 1950-1994. J Cancer Res Clin Oncol 1995;121: 535-541. 